\title{
STUDY AND DESIGN OF PORTABLE ANTIMICROBIAL WATER FILTER
}

\section{SHIVANI BATRA, PRIYANKA ADHIKARI, ANCHIT GHAI*, AMAN SHARMA, RHEA SARMA, SUNEETHA V}

Department of Biotechnology, Vellore Institute of Technology, Vellore, Tamil Nadu, India. Email: anchitghai@gmail.com

\author{
Received: 13 May 2017, Revised and Accepted: 30 May 2017
}

\begin{abstract}
Objective: This study was conducted to design a portable antimicrobial water filter which is both economic and easy to use.

Methods: A prototype following the designing of the water filter was constructed. Layers of sand, cloth, activated charcoal, and cotton containing compartments were built for carrying out water analysis.
\end{abstract}

Results: Most probable number index of Vellore Institute of Technology lake water was compared with that of filtered water. Complete water analysis was done, and the sand filter layer was observed to be responsible for a maximum of the antimicrobial action of the filter.

Conclusion: The study demonstrated that the proposed design of water filter is efficient in removal of turbidity, odor, and microbial content of lake water along with decreasing the acidity of water.

Keywords: Water filter, Antimicrobial, Tulsi (Ocimum tenuiflorum), Guava (Psidium guajava), Neem (Azadirachta indica) and Duranta repens, Compartmentalized filter design, Portable.

(C) 2017 The Authors. Published by Innovare Academic Sciences Pvt Ltd. This is an open access article under the CC BY license (http://creativecommons. org/licenses/by/4. 0/) DOI: http://dx.doi.org/10.22159/ajpcr.2017.v10i9.19925.

\section{INTRODUCTION}

Most of the water present on this earth is not fit for human use as $97 \%$ of it is saline water. Water scarcity affects every continent and around 2.8 billion people around the world at least 1 month every year. More than 1.2 billion people lack access to clean drinking water. It is estimated that more than half of the world's population will be at risk of water shortages if the current trends continue. Out of the 575,000 Indian villages, about 162,000 face problems of contaminated and shortage of water.

The purpose of this project is to design a portable water purifier to diminish microbial contents in the sample with the help of nature. The motivation of this project is the inability of poor people to afford expensive electrical water purifiers along with many situations or places where a portable water purifier is needed for deriving potable water from untreated sources.

Different areas have different problems and resources, and one solution cannot be applied to all. Water is often pumped from a nearby lake or from groundwater, which may contain various pathogens, carcinogens, dissolved impurities, mineral ions, and particulate matter.

Conventional water purification methods are proving to be insufficient to supply clean water as the demand keeps growing. Moreover, current methods of water purification are energy intensive and hence can be installed only in specific areas. To tackle these problems, we aim to create a water filter that does not require energy input. In addition to the physical purification aspects, we intend to deal with the microbial aspects too. Using leaves of plants that are easily available, we intend to assess and utilize the antimicrobial properties that these leaves possess.

Our end result will be a water filter (Fig. 1) that can purify water of both physical and biological impurities without requiring energy input. This will help the people living in remote and poverty struck areas reap the benefits of this water filter. The components used in our filter are easily available and easily replaceable. The filter is compartmentalized so that any component of the filter may be easily replaced within minutes without compromising the integrity if the filter. The filter requires negligible technical knowledge to operate and has been designed as such, keeping in mind that the targeted population is principally uneducated and lacks technical knowledge.

\section{METHODS}

\section{Design}

The water filter designed has four compartments which can easily be cleaned and refilled with respective contents of the compartments. Plastic bottles were cut and used for compartmentalization of the filter to make a design which is easy to use and does not require much technical knowledge. The filter has each compartment with a cap (Fig. 2) and an open end to provide the user with an easy way to clean the filter without professional help. Furthermore, the filter was designed in such a way that it is economical and affordable for common people.

The first compartment is specifically for primary filtration of the water and has a muslin cloth layer which helps in separating the big physical impurities from it. For further filtration, a layer of mesh on the cap of the bottle is added. The second compartment (Fig. 3) was composed of sand and gravel succeeded by multiple layers of muslin cloth filter. The cap of this compartment also has a mesh layer on it to prevent the flow of fibers or sand particles with water. The third compartment has a cloth filter, followed by a filter composed of plant leaf extracts exhibiting antimicrobial effects. The cap of this compartment also has a mesh attached. The fourth compartment (Fig. 4) has activated charcoal which helps in removing the foul smell, ionic dyes [1] as well as the gasses produced by the microbes in the water. After the activated charcoal layer, there are multiple layers of non-absorbent cotton, which helps in preventing the flow of charcoal particles along with water.

\section{Activated charcoal}

Carbon is an extremely porous material that attracts and holds a wide range of harmful contaminants. Activated carbon is carbon which has a slight electropositive charge added to it, making it even more attractive to chemicals and impurities. As the water passes over the positively charged carbon surface, the negative ions of the contaminants are drawn to the surface of the carbon granules $[1,2]$. It removes chlorine, 
sediments, and volatile organic compounds that cause pollutionand bad odor and improve tastes $[3,4]$.

Activated carbon removes contaminants from water by two mechanisms, adsorption for removal of organic compounds and catalytic reduction involving the attraction of negatively-charged contaminant ions to the positively-charged activated carbon in the removal of residual disinfectants such as chlorine and chloramine. However, it is not effective in removal of minerals, salts, and dissolved inorganic compounds, and so, hardness cannot be removed.

\section{Cotton}

Cotton aids removal of further persistent turbidity. It prevents the flow of activated charcoal particles further down in the filter. It reduces color imparted to water by carbon layer.

\section{Sand}

It removes coliform bacteria, algae, color, and iron and manganese content of water $[3,5]$. Sand filters work using a complex biological film that grows naturally on the surface of the sand which merely functions as a substrate for the filtration. Slow sand filters work through the formation of a gelatinous layer or biofilm on the top of a layer of fine sand which consists of bacteria, fungi, and protozoa [6]. The surface biofilm is the layer that provides the effective purification in potable water treatment, the underlying sand providing the support medium for this biological treatment layer. As water passes through the hypogeal layer, particles of foreign matter are trapped in the mucilaginous matrix and soluble organic material is adsorbed. The contaminants are metabolized by the bacteria, fungi, and protozoa. The water produced from a slow sand filter is expected to be of excellent quality with significant bacterial cell count reduction [4].

\section{Cloth layer}

The pore size in an old sari cloth is $100-150 \mu \mathrm{m}$ which can be decreased to about $20 \mu \mathrm{m}$ if the cloth is folded 4-8 times. The pores allow water to pass but retain particles and pathogens with size greater than the pore size. Our model employed the use of cloth cut in thin strips which needs to be regularly washed after use and replaced in case of holes or tears.

\section{pH test}

The $\mathrm{pH}$ of water sample of lake water as well as that of filtered water was found using a $\mathrm{pH}$ meter.

\section{Presumptive test}

Most probable number (MPN) test was performed for lake water as well as water obtained after passage through the filter. Each water sample was serially diluted to $10 \mathrm{~mL}, 1 \mathrm{~mL}$, and $0.1 \mathrm{~mL}$ along with Luria broth in 5 test tubes of each batch. Durham's tubes were also introduced into each test tube. Both sets at $37^{\circ} \mathrm{C}$ for about $36-48 \mathrm{hrs}$ and results were obtained.

\section{Confirmation test}

Eosin methylene blue (EMB) agar was prepared by adding $3.6 \mathrm{~g}$ of EMB agar powder in $200 \mathrm{~mL}$ of distilled water, and glass Petri plates were inoculated with 24 hrs positive presumptive test culture with a sterile inoculating loop to be incubated.

\section{Completed test}

The positive result of the confirmatory test (EMB test) was transferred to MacConkey agar prepared by adding ( $9.8 \mathrm{~g}$ of MacConkey agar powder in $200 \mathrm{~mL}$ of distilled water) and incubated at $37^{\circ} \mathrm{C}$ for $24 \mathrm{hrs}$.

\section{Testing antibiotic properties of leaves}

Leaves of Tulsi (Ocimum tenuiflorum), Guava (Psidium guajava) $[7,8]$, Neem (Azadirachta indica) $[9,10,6]$, and Duranta repens [11] were tested for antibacterial properties by preparing a leaf extract of each of the leaf samples. Small filter paper tablets were dipped in water extract solution each leaf to make an extract tablet. This along with a whole dried leaf was taken to test for the zone of inhibition when placed on a Petri plate containing Nutrient Agar $(2.8 \mathrm{~g} / 100 \mathrm{~mL})$ streaked with serially diluted lake water. These plates were incubated at $37^{\circ} \mathrm{C}$ for 24 hrs and observed.

\section{RESULTS}

\section{pH test}

The $\mathrm{pH}$ of the water sample from Vellore Institute of Technology lake was found to be 5.26. This filter was also beneficial in reducing the acidity of water by taking $\mathrm{pH}$ of the filtered water to $\mathrm{pH} 6.92$ bringing it within the approved range of $\mathrm{pH}$ of 6.5-8.5 (Table 1).

\section{Presumptive tests}

MPN score for lake water was taken as 5-5-0 corresponding to MPN index of $240 / \mathrm{mL}$. MPN score for filtered water was found to be 3-2-1 corresponding to MPN index of $17 / \mathrm{mL}$ showing a significant reduction in the microbial content of water (Table 1 ).

\section{Confirmation test}

A characteristic green sheen of colonies (blue-black in some cases) was obtained on Petri plates streaked with lake water as well as those streaked with water after passage from filter and charcoal layer. As in the previous test, the number of colonies was reduced in the case of water from the filter.

The colonies obtained were identified as those of Escherichia coli based on a characteristic metallic blue-black sheen with a dark center.

Table 1: Physical analysis of water samples

\begin{tabular}{|c|c|c|c|c|}
\hline $\begin{array}{l}\text { Sample } \\
\text { taken }\end{array}$ & pH & Odor & Turbidity & $\begin{array}{l}\text { MPN index } \\
\text { per } \mathbf{m L}\end{array}$ \\
\hline $\begin{array}{l}\text { Lake } \\
\text { water }\end{array}$ & 5.26 & Foul odor & $\begin{array}{l}\text { Presence of small } \\
\text { particulate matter }\end{array}$ & 240 \\
\hline $\begin{array}{l}\text { Filtered } \\
\text { water }\end{array}$ & 6.92 & $\begin{array}{l}\text { Minimized } \\
\text { odor }\end{array}$ & Absence of turbidity & 17 \\
\hline
\end{tabular}

MPN: Most probable number

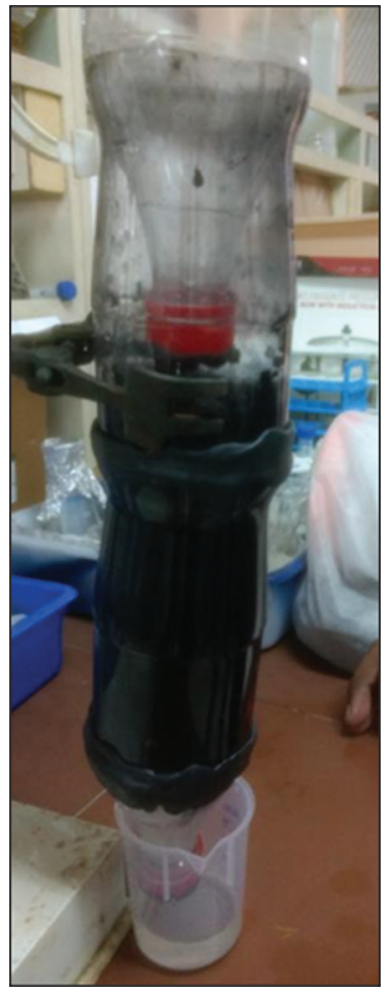

Fig. 1: Assembled filter 


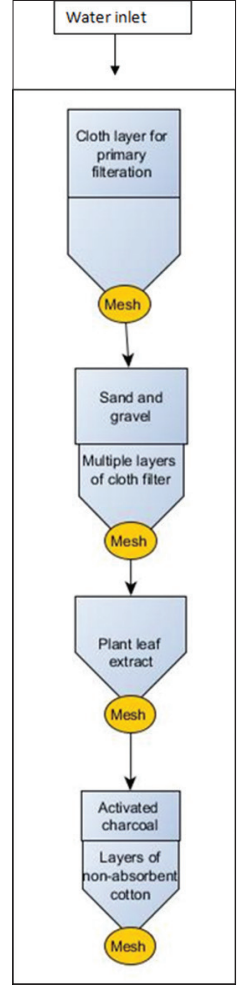

Fig. 2: Design of the water filter

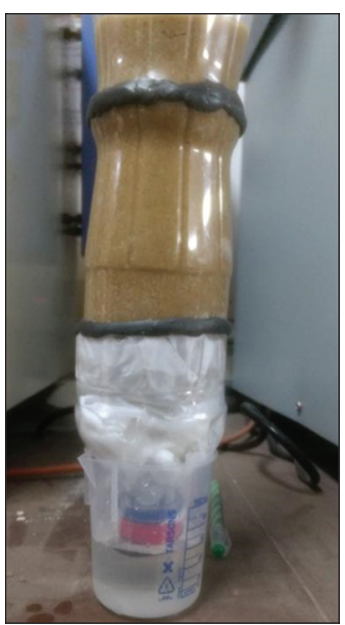

Fig. 3: Sand and gravel layer and cloth layer compartment

\section{Completed test}

Pink, non-mucoid colonies were obtained which signified the predominant presence of Gram-negative, lactose-producing E. coli in water samples. The maximum number of such colonies were observed in the case of Petri plate containing lake water sample. Growth and number of such colonies were seen to be reduced in the Petri plates containing water after passage from filter and charcoal layer alone.

Since a number of colonies were significantly lesser in Petri plate containing water from the filter as compared to that of water from the charcoal layer, it was concluded that the sand layer was most responsible for a decrease in microbial content after the passage of water from the filter.

\section{Testing antibiotic properties of leaves}

Insignificant zones of inhibition in comparison to those normally found by the antibiotic activity of common antibiotics due to the low

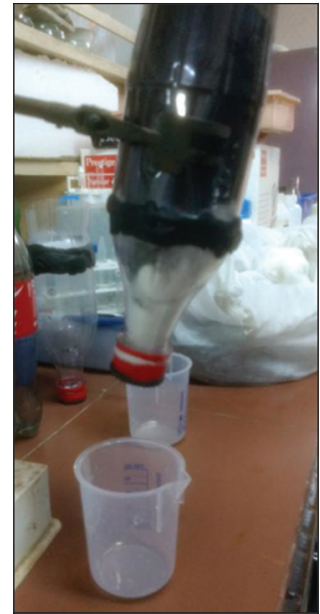

Fig. 4: Activated charcoal layer and cotton layer compartment

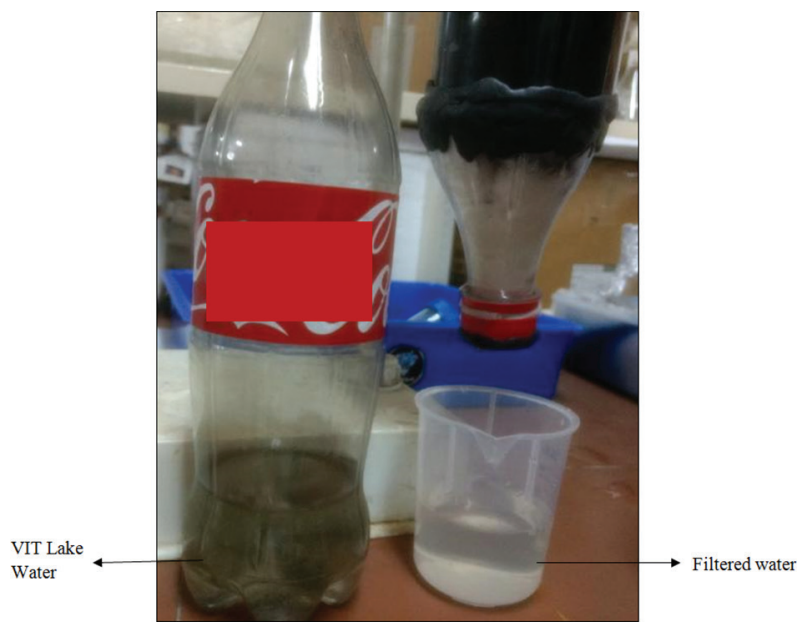

Fig. 5: Lake water (left) and filtered water (right)

concentration of leaf in the water extract. It was, therefore, further proposed that an acetone [10] or methanol extract of leaf in the form of a layer could be incorporated within the filter which along with being easy to replace will also exhibit greater antibacterial activity.

\section{DISCUSSION}

The economics involved in the manufacture of the water filter designed are elucidated on further.

The Indian Government states that $22 \%$ of the population is under its official poverty line. Any industry or company that chooses to manufacture our product will have a huge consumer base that already exists but needs to be tapped into. The poor people, who are the primary stakeholder in this project, are benefitted as there is now a cheap an affordable water filter in the market which does not run on electricity.

The highest price of plastic that has been recorded in the past 2 months is Rs. 25 for $1 \mathrm{~kg}$. It takes 25 polyethylene terephthalate (PET) bottles to make up to $18 \mathrm{~g}$. Hence, $1 \mathrm{~kg}$ has around 1388 plastic bottles. By that logic, we can procure 1388 PET bottles for only Rs. 25 to make 347 proposed filters. The cost of activated charcoal for $1 \mathrm{~kg}$ is Rs. 120. Each filter requires around half a kg of charcoal brings the cost of charcoal used in our filter to about Rs. 80. River sand costs Rs. $43 / \mathrm{kg}$. If around half $\mathrm{kg}$ is used, the cost of sand amounts to Rs. 22. Cotton costs around Rs. 220/kg. If around half kg again is used again, the cost amounts to Rs. 110. 
Pumice stone costs about Rs. $10 / \mathrm{kg}$ in bulk. If we use around $200 \mathrm{~g}$, the cost would be Rs. 2 .

Hence, the total cost of filter taking the most pessimistic costs that may exist in the market. 1 filter should be around Rs. 250 .

Some notable features of the filter include:

- Coloration of water was minimized after passage through the charcoal column and other natural layers.

- Each component of the filter is compartmentalized, thus making cleaning and replacing components easy.

- Expected to take around $2 \mathrm{hrs}$ to filter $1 \mathrm{~L}$ of water.

Advantages of the filter:

- Components can be easily replaced as they are compartmentalized.

- Most components are easily available.

- The plants used in the microbiological aspect are found frequently in Indian environments.

- The filtrate achieved will be odorless, colorless, and free of microbes and will have a neutral $\mathrm{pH}$.

- Highly economical.

- Does not require electricity or skilled technical knowledge to operate.

\section{CONCLUSION}

The study demonstrated that the proposed design of water filter is efficient in removal of turbidity, odor, , (Fig. 5) and microbial content of lake water along with decreasing the acidity of water. This paper contains a brief preliminary of the compartmentalized water filter

This project can be taken along further in which the antimicrobial aspect of the filter will be further worked on. Much work still needs to be done regarding the leaf layer and subsequent tests to quantify the water purification properties of this filter.

Some additional improvements can also be added to the filter keeping the subsequent increase in the price of a filter in mind. A pumice stone compartment can be introduced since pumice stone has several advantages over other traditional filter methods.

\section{ACKNOWLEDGMENT}

The authors also want to express sincere gratitude to honorable Chancellor Dr. G. Viswanathan and our respected Vice-President Dr. Sekar Viswanathan and Mr. G. V. Selvam for their constant support and encouragement.

\section{REFERENCES}

1. Agalya A, Palanisamy PN, Sivakumar P. Kinetics, equilibrium studies on removal of ionic dyes using a novel non-conventional activated carbon. J Chem Res 2012;3(1):62-8.

2. Rivera-Utrilla J, Sánchez-Polo M, Gómez-Serrano V, Álvarezc PM, Alvim-Ferraz MC, Dias JM. Activated carbon modifications to enhance its water treatment applications. An overview. J Hazard Mater 2011;187(1-3):1-23.

3. Nataraj HM, Gupta NV, Ravi G. Validation of water purification system. Asian J Pharm Clin Res 2017;10(4):409-16.

4. Dalahmeh SS, Nsson HJ, Hylander LD, Hui N, Yu D, Pell M. Dynamics and functions of bacterial communities in bark, charcoal and sand filters treating greywater. Water Res 2014;54:21-32.

5. Logsdon GS, Kohne R, Abel S, Labonde S. Slow sand filtration for small water systems. J Environ Eng Sci 2002;1(5):339-48.

6. Gupta Y, Sharma D, Sharma Y. Bactericidal activity of different parts of Azadirachta indica on probiotic microbes. Asian J Pharm Clin Res 2016;9 Suppl 1:50-3

7. Philip CD, Kumari RI, Lavanya B. Phytochemical analysis, antioxidant and anti-microbial activity of white \& pink Psidium guajava Linnaeus. Int J Curr Pharm Res 2015;7(2):29-31

8. Anjana AK, Francis P, Gomathy S, Vijayan SK, Mohammed M, Chandrasekar MJ. In vitro antiviral screening of Psidium gujava L. Against Hsv-1 and Hsv-2 by Cpe inhibition assay. Asian J Pharm Clin Res 2014;7(1):102-4

9. Krishnan Y, Wong NK. Cytotoxicity and antimicrobial properties of neem (Azadirachta indica) leaf extracts. Int J Pharm Pharm Sci 2014;7(2):179-82

10. Gnanakalai K, Gopal R. Phytochemical constituents and in vitro antibacterial activity of various extract of Azardirachta indica (neem). Int J Curr Pharm Res 2016;8(3):52-5.

11. Savithramma N, Yugandhar P, Suhrulatha D. Traditional medicinal plants used by local people of Kailasakona - A sacred grove of Chittoor district, Andhra Pradesh, India. Int J Pharm Pharm Sci 2015;7(3):407-11. 